\title{
Yves Clavaron, Le génie de l'Italie
}

\section{Emanuele Kanceff}

\section{(2) OpenEdition}

\section{Journals}

\section{Edizione digitale}

URL: https://journals.openedition.org/studifrancesi/26767

DOI: 10.4000/studifrancesi.26767

ISSN: 2421-5856

\section{Editore}

Rosenberg \& Sellier

\section{Edizione cartacea}

Data di pubblicazione: 1 avril 2007

Paginazione: 210

ISSN: 0039-2944

\section{Notizia bibliografica digitale}

Emanuele Kanceff, «Yves Clavaron, Le génie de l'Italie», Studi Francesi [Online], 151 (LI | I) | 2007, online dal 30 novembre 2015, consultato il 23 novembre 2021. URL: http://journals.openedition.org/ studifrancesi/26767 ; DOI: https://doi.org/10.4000/studifrancesi.26767

\section{Questo documento è stato generato automaticamente il 23 novembre 2021.}

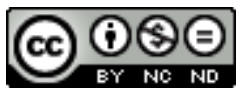

Studi Francesi è distribuita con Licenza Creative Commons Attribuzione - Non commerciale - Non opere derivate 4.0 Internazionale. 


\title{
Yves Clavaron, Le génie de l'Italie
}

\author{
Emanuele Kanceff
}

\section{NOTIZIA}

yVES CLAVARON, Le génie de l'Italie. Géographie littéraire de l'Italie à partir des littératures américaine, britannique et française (1890-1940), Paris, Éditions Connaissances et Savoirs, 2006, pp. 557 (ma 561).

1 Péladan sosteneva che non fosse bene venire in Italia, perché non è bello conoscere quello che si è troppo amato con l'immaginazione. Se ci si ricorda di quanto diceva Gœthe, si può capire Péladan (non consenzienti). Soprattutto, si può valutare meglio questo libro, sorta di storia-critica del viaggio in Italia dedicato tutto al mito dell'Italia, nelle sue infinite modalità e sfaccettature. Una statistica recente, che non ho avuto cura di verificare, attribuisce all'Italia all'incirca il 70 per cento dei beni culturali esistenti al mondo. Ciò che invece ho potuto verificare è che circa il 70 per cento di tutti i viaggi letterari o culturali o che comunque abbiano lasciato tracce intellettuali - sono stati viaggi in Italia. È ciò che pare anche sostenere genericamente Yves Clavaron quando afferma che esistono pochi paesi al mondo (io avrei detto nessuno) che abbiano fatto scorrere tanto inchiostro quanto l'Italia, «un pays-livre avant d'être un pays libre». In questo grandioso libro-paese l'autore scorrazza con minuziosa cultura e sarebbe impresa folle voler discernere quanto attiene specificamente all'area francofona: comparatismo letterario bello e buono, così come si richiede agli studiosi del viaggio in Italia che non vogliano condannarsi a non comprendere e peggio rispondere. In quello sconfinato orizzonte di immagini letterarie che hanno espresso le Italie degli europei Clavaron trascorre con competente piacere, guidato dall'idea-cardine del quartetto, le quattro mete reali e della fantasia. Venezia, come poteva non essere la prima meta? Venezia la città-specchio, città della morte e della perdizione ma anche trionfale nel suo fascino. E poi Firenze, fiore della Toscana e dell'Umbria, della Rinascenza ritrovata, dell'Etruria misteriosa, delle flâneries appaganti e delle camere con vista sui colli. E Roma, la capitale impossibile, la città di tutti e contesa, la città dalle tre dimensioni e dal sapore di eternità. Infine Napoli, l'inquietante straniera del Sud, sempre ambigua e 
misteriosa nel suo assetto mediterraneo, città degli amori e degli archetipi dall'impenetrabile passato.

2 Ma l'Italia non è fatta solo di quattro splendide città dall'indubbia carica letteraria: è fatta anche di periferie, di confini, di sperduti orizzonti nordici e di affascinante mezzogiorno, di ricchissime dimensioni insulari che, da sole, sarebbero sufficienti ad esprimerla.

3 E, per finire, l'Italia è fatta di grandi miti, di paesaggi del cuore, di feste dell'anima e del corpo, di paganesimo e di misticismo, di virilità e di malattia, di un curioso compromesso latino tra l'Angelo e la Bestia: paese ove il razionale cede senza stridere alla forza delle cose e l'equilibrio interiore viene capovolto senza rimpianti. Non so se queste cinquecento pagine di dissolvenze letterarie nelle immagini della storia esprimano veramente il "genio" dell'Italia ma certo ne sono un ritratto suggetivo. 